\title{
Kıyı Akiferlerinde Tuzlu Su Girişimi Etkisi ve Yeraltı Barajları: Bir Literatür İncelemesi
}

\author{
${ }^{1}$ Serin Değerli ve ${ }^{* 1}$ Evren Turhan \\ ${ }^{1}$ Adana Alparslan Türkeş Bilim ve Teknoloji Üniversitesi, İnşaat Mühendisliği Bölümü, Adana, TÜRKİYE
}

\section{Özet}

Kıyı bölgeleri, ticaret ağlarına kolay ulaşımı ve verimli toprakları sayesinde Dünya nüfusunun yaklaşık yarısını üzerinde barındırmaktadır. Sahil şeridinde biriken yoğun canlı nüfusunun temel su ihtiyaçlarının karşılanabilmesi için yeraltı tatlı su kaynakları sıklıkla tercih edilmektedir. Ancak yeraltı akiferlerinin deşarj hızının yüzeysel su kaynaklarına kıyasla çok daha az olmasından dolayı kontrolsüz kullanım sonucunda akiferlerde tuzlu su girişimi problemi ortaya çıkabilmektedir. Bu çalışma, yeraltı suyu akımına tuzlu su girişimi ile ilgili literatürdeki çalışmaların detaylı bir şekilde incelenmesi ve ileriye dönük önerilerde bulunmak amacıyla yapılmıştır. Literatür ayrıntılı incelendiğinde yeraltı akım dinamiğinde tuzlu su girişimine bağlı olarak oluşan akım davranışını nümerik ve deneysel olarak ele alan çalışmalar olduğu görülebilmektedir. Sonuç olarak Türkiye'deki kıyıya yakın birçok drenaj havzasında su kullanımına bağlı olarak böyle bir yeraltı suyu kirliliği sorunu meydana gelebilecektir. Yeraltı barajlarının yapımı su ihtiyacının karşılanması noktasında ve kuraklıkla mücadelede önemli çözümler olarak düşünülebilir.

Anahtar Kelimeler: Yeraltı suyu akımı, tuzlu su girişimi, yeraltı barajı, geçirimsiz duvar

\section{Saltwater Intrusion Effect and Subsurface Dams in Coastal Aquifers: A Literature Review}

\begin{abstract}
Due to being the center of trade networks and fertile lands, almost half of the human population is located in coastal areas. To meet the requirement of fresh water in densely populated locations, aquifers are commonly preferred. However, owing to the fact that the discharge velocity of aquifers is much lower compared to surface flow, salt water intrusion problem may occur in the aquifers as a result of uncontrolled water usage. This study was carried out in order to investigate the studies in the literature on salt water intrusion into the groundwater flow detailed and to give forward suggestions. When the literature is examined elaborated, it can be seen that there are studies that perform the flow behavior due to salt water intrusion in subsurface flow numerically and experimentally. Consequently, such a groundwater pollution problem may occur due to exceed water use in many coastal drainage basins in Turkey. The building of underground dams can be considered as substantial solutions to meet the water needs and to struggle with drought.
\end{abstract}

Keywords: Ground water flow, saltwater intrusion, subsurface dam, cutoff wall

\footnotetext{
${ }^{*}$ Corresponding author: Address: Faculty of Engineering, Department of Civil Engineering Adana Alparslan Türkeş Science and Technology University, 01250, Adana TURKEY. E-mail address: eturhan@atu.edu.tr, Phone:
}

$+903224550000-2048$ 


\section{Giriş}

Artan nüfus ve küresel çapta gözlenen sıcaklık artışı nedeniyle, günümüzde kişi başına düşen su miktarı açısından Türkiye orta risk kategorisinde yer almakta, ilerleyen zamanlarda ciddi su kıtlığı tehlikesi ile karşı karşıyadır [1]. Bu durum her geçen gün su kaynaklarının daha verimli kullanılması gerektiğinin önemini ortaya koymaktadır. Su ihtiyacının karşılanabilmesi için rezervuar veya hazne tasarımı kurak dönemlerde su kaynaklarından faydalanılmasına olanak vermektedir. Eğer hazne bir gölet olarak tasarlanmışsa baraj yerüstü baraj1, yeraltında konumlandırılmış ise yeraltı barajı olarak nitelendirilir (Şekil 1) [2]. Yeraltı barajları; permeabilitesi sıfır olan geçirimsiz tabakanın üstünde, engelleyici bir yapı ile yeraltı suyu akışını sınırlandırarak doğal veya yapay akifer içerisinde suyun biriktirilmesini sağlayan hidrolik yapılardır [3]. Böylece çeşitli amaçlarla kullanılacak olan suyun depolandığı bu tip barajlarda genellikle doğal bir akarsu hattı üzerine inşa edilerek gerekli suyun biriktirilmesi hedeflenir. Ancak akarsular tatlı su kaynaklarının sadece \%0.3'ünü oluşturmakta, buna karşın akifer rezervi toplam tatlı su miktarının yaklaşık \%30'una denk gelmektedir [4]. Buna bağlı olarak gelecekteki su ihtiyacını karşılayabilmek için yeraltı suyundan faydalanılması üzerinde durulmaya başlanmıştır [5].

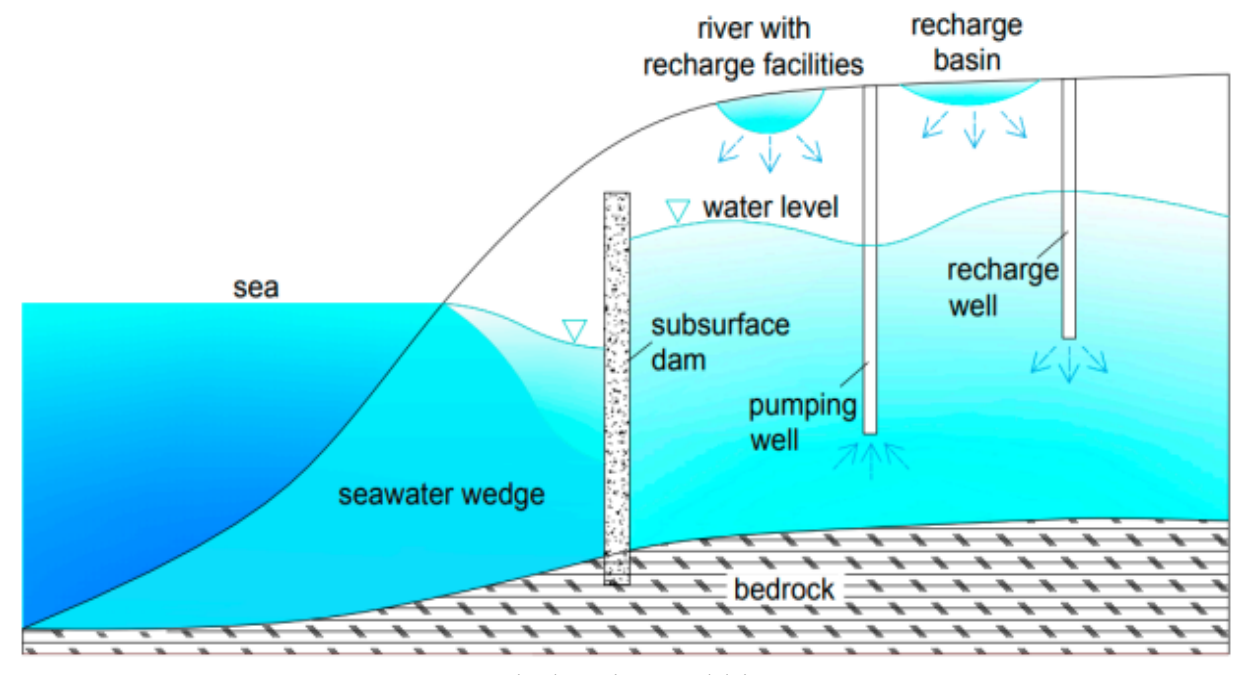

Şekil 1. Yeraltı barajı genel bir görünüş [2]

Yeraltı barajları, tatlı su akiferlerinden su elde etmenin başlıca yöntemlerinden birisidir. Kendi içerisinde geçirimsiz perde (cut-off wall) ve tersip bendi (sand storage dam) olarak ikiye ayrılmaktadır. Tersip bentleri akarsu akımı ile taşınan sedimentin depolanması amacıyla tasarlanır, ancak ekonomik ömrünün sonunda bent arkasında biriken sediment hazneyi tamamen doldurur. Bu durumda yapay bir akifer elde edilmiş olunur ve bent arkasında biriken su ve sedimentin permeabilitesi yüksek ise pompa yardımıyla kullanıma sunulabilir [6].

Yüzeysel kaynaklara kıyasla daha fazla tatlı su barındırmasına rağmen yeraltı barajlarının kendi içerisinde avantajları ve dezavantajları bulunmaktadır. Gölet rezervuarları için büyük tarım ve yaşam alanlarının tahliye edilmesi gerekebilir, yeraltı barajlarında hazne herhangi bir alanı işgal etmeyeceği için çoğu zaman böyle bir sorun ile karşılaşılmaz. Yeraltı barajlarında engelin memba 
ile mansabı granüler malzeme ile dolu olduğu için barajın yıkılması durumunda katastrofik taşkınlar pek görülmez. Yerüstü barajlarında ölü hacim ekonomik ömür sonunda tüm hazneyi doldurarak barajdan faydalanılmasına engel olmaktadır, ancak yeraltı barajında hazne söz konusu malzeme ile dolu olduğu için bu durum engellenmiş olmaktadır. Güneş 1şığ 1 ile teması bulunmadığı için de buharlaşma ve ötrifikasyon olayları yeraltı barajlarında ihmal edilebilecek düzeylerdedir. Yeraltı barajları hem maliyet hem de proje süresi olarak yerüstü barajlarına göre çoğunlukla avantaj sağlamaktadır [7].

Yeraltı barajının yerüstü barajına göre bazı dezavantajları da tabi ki mevcuttur. Buna bir örnek olarak, bir akarsuyun debi miktarı muline ve su derinliği yardımıyla çok kolay bir şekilde ölçülebilirken bir yeraltı akiferinin geri beslenme süresini ve kapasitesini belirlemek daha zordur. Yeraltı barajının gerisinde su seviyesi zemin yüzey kotuna üzerine çıkacak kadar yükselirse yüzeyde bataklık oluşumuna sebep olabilir [8]. Yerüstü barajlarında hazne atmosfere açık olduğu için dış etkenler tarafından kirletilmeye maruz kalabilir, yeraltı barajlarında bu durum bir miktar daha kontrol altında olmasına rağmen kıyı bölgelerde tuzlu su girişimi (saltwater intrusion) akifer dengesini tehdit edebilmektedir (Şekil 2) [9, 10, 11, 12].

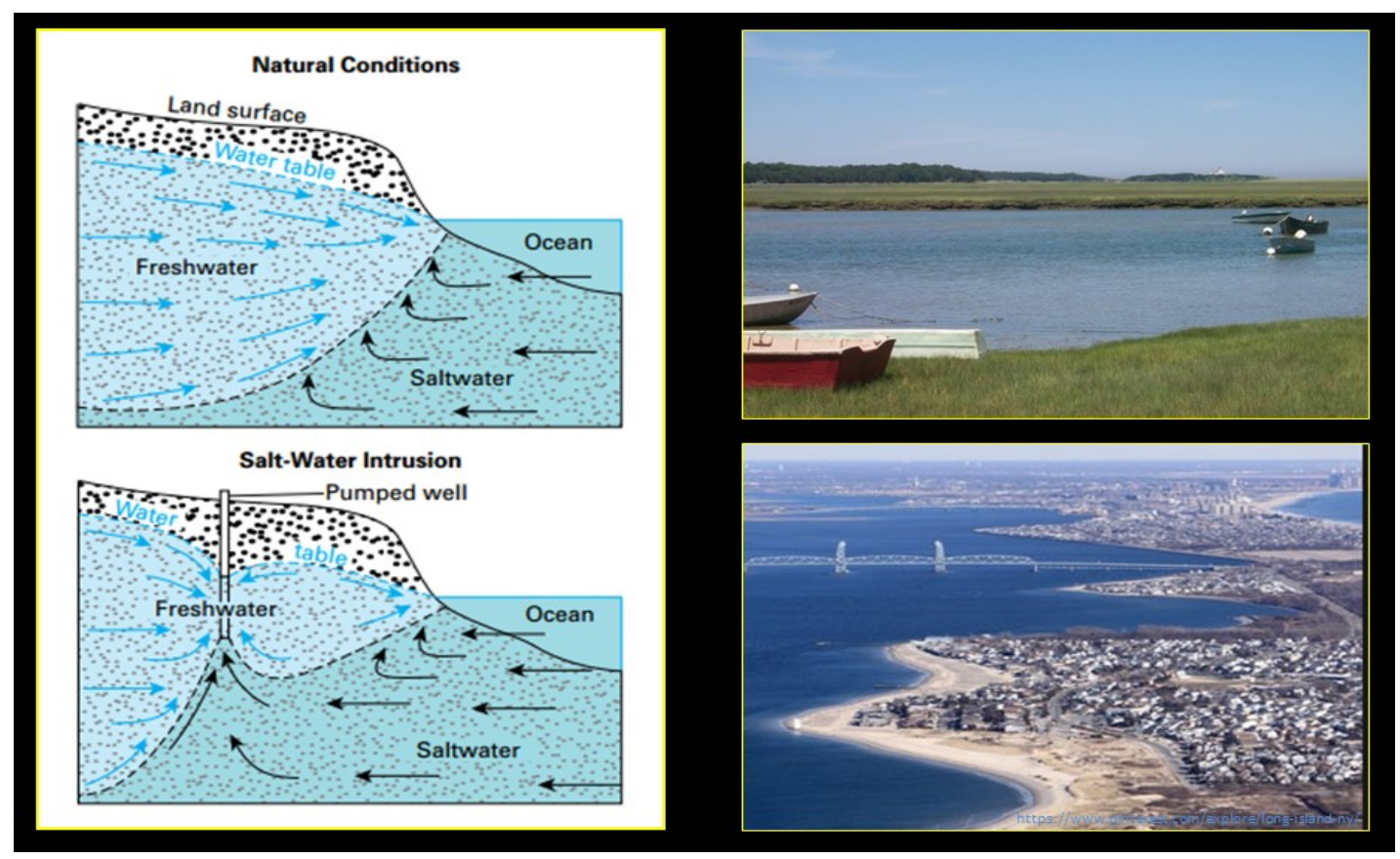

Şekil 2. Kiyılarda tuzlu su girişimi etkileri [9]

Çoğu kurak ve yarı kurak bölgede, su ihtiyacının karşılanması için yeraltı suyu kullanımının artması sonucunda düşük rakımlı deniz suyunun akifere karıştı̆̆ bölgelerde tuzlu su girişimi problemi ile karşı karşıya kalınabilmektedir [13]. Tuzlu su girişimi olması halinde tatlı su kaynağı olarak faydalanılan akiferler kirlenerek kullanılmaz hale gelebilmektedir ve Dünya nüfusunun yaklaşık \%50'lik kısmının kıyı şeridine yakın bölgelerde ikamet ediyor olması tuzlu su girişiminin çok daha detaylı incelenerek önlemlerin alınmasını gerektirmektedir [14]. Tuzlu su girişimini tetikleyen faktörler; buzulların erimesi ile deniz seviyesindeki yükselme, fırtına ve gelgit döngüsü, kuraklık, kontrolsüz su tüketimi ve su dağıtım sistemleri olmak üzere beş kategoriye 
ayrılmıştır $[15,16]$. Global olarak artan ortalama sıcaklık nedeniyle her sene deniz seviyesi bir miktar daha artmaktadır. Bu durum kıyı bölgelerindeki yeraltı su kaynaklarının ve buna bağlı olarak da tarım arazilerini tuzluluk tehlikesi ile karşı karşıya bırakabilmektedir. Kıyı akiferlerinde tuzlanmaya sebep olan bir başka durum ise kontrolsüz su kullanımıdır. Normal durumda gözenekli zemin yapısında depolanan su kütlesi tabakalarının eğimi denize doğru olduğu için yerçekimi etkisiyle tatlı su ile tuzlu su bir karışım bölgesi oluşturur, bu durum yeraltı akiferlerinin mineral ihtiyacını karşılamak ve deniz suyunun da tuzluluk dengesini korumak için gerekli olan belli bir miktar tuzlu su alışverişinin gerçekleşmesini sağlar [17]. Ancak akiferden büyük miktarlarda su çekilmesi durumunda akifer içerisinde negatif basınç oluşur ve vakum etkisi ile akifere hızlı bir şekilde tuzlu su girişimi olmaktadır. Tuzlu suyun tatlı suya göre daha yoğun olması sebebiyle kıyı bölgelerde deniz suyu akiferin alt kısımlarından yayılım göstermektedir $[18,19]$. Tuzlu su kıyıya komşu olan bölgelerin iç kısımlarına kanallarla ve gelgit geçitleri vasıtasıyla taşınabilir [20]. Başlangıçta tatlı suyun iletimi amacıyla tasarlanan bu hidrolik yapılar; kuraklık ve deniz suyu yükselmesi ile kıyıya komşu olmayan iç kısımların da tuzlanmasina sebebiyet verebilmektedir [16, 21].

Tuzlu su girişiminin önlenmesine yönelik çeşitli çözüm yöntemleri mevcut olup, bunlara; su kullanımının sınırlandırılması, kuyu konumlarının değiştirilmesi, hidrolik ve fiziksel bariyerler örnek olarak verilebilir [22]. Fiziksel bariyerlerin geçmişte sıklıkla tercih edilen bir yöntem olmamasından kaynaklı olarak, yeraltı akımı üzerindeki etkisinin incelenmesini konu alan çalışmaların artması literatüre katkı anlamında büyük önem taşıyabilecektir (Şekil 3) [7].
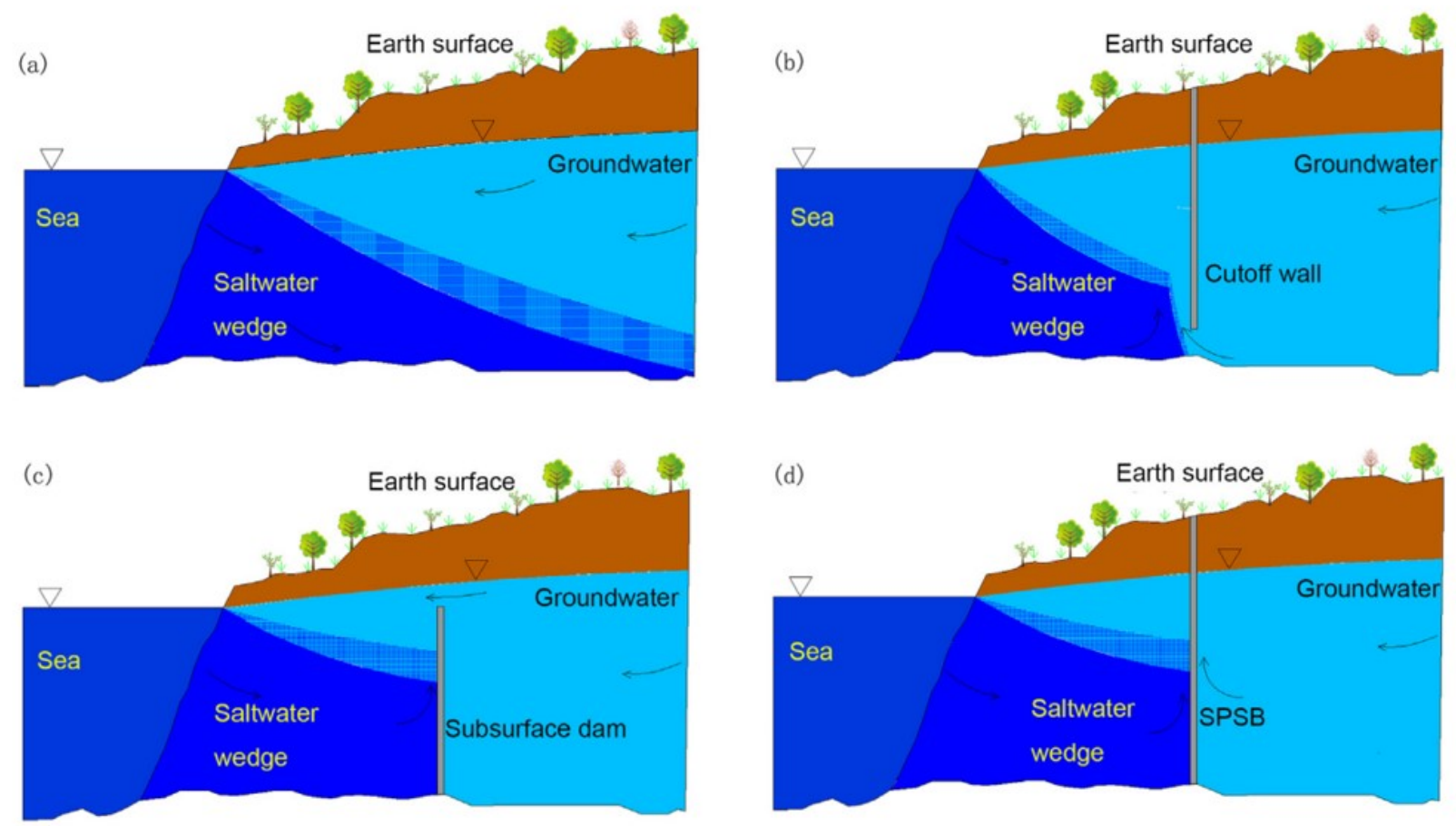

Şekil 3. Yeraltı fiziksel bariyer çeşitleri [7]

$\mathrm{Bu}$ çalışma kapsamında, bir yeraltı akımına tuzlu su girişimi olması halinde bu durumun akım hareketini nasıl etkilediğini belirten literatürdeki sayısal ve deneysel çalışmaların ele alınması 
sonucunda gelecek çalışmalar açısından yol gösterici olmasına özen gösterilmiştir.

\section{Nümerik Modelleme ve Deneysel Literatür Çalışmaları}

Huyakorn ve ark. [23] kıyı akifer sistemlerinde tuzlu su girişimini simüle etmek için keskin bir arayüz kamasının sayısal modelini geliştirmişlerdir. Oluşturdukları model yeraltı suyu akımı ile tuzlu su arasında bir arayüz olduğunu varsayarak akış hareketini temsil etmektedir. Sonlu elemanlar yöntemini kullanarak oluşturulan modelin, yeraltı suyu ile tuzlu su ara yüzünün yerini, yanal hareketini ve yukarı akışını takip etmede doğru sonuçlar verdiğini gözlemlemişlerdir. Oude Essink [14] çalışmasında Hollanda'nın Noord-Holland bölgesinin kuzey kıyısında yeraltı akımındaki tuzlu su girişimini araştırmıştır. Yoğunluğa bağlı olarak modelleme yapılmasını sağlayan MOCDENS3D yazılımını kullanarak yeraltı suyu akımını üç boyutlu simüle etmiştir. Yapılan inceleme sonucunda Hollanda kıyı bölgelerinde ciddi miktarda tuzluluk belirtileri olduğunu gözlemlemiştir. Goswami ve Clement [24] çalışmalarında tatlı su akiferinde tuzlu suyun gelişimini, küçük ölçekli bir laboratuvar düzeneğinde gözenekli bir ortam oluşturarak incelemişlerdir (Şekil 4).

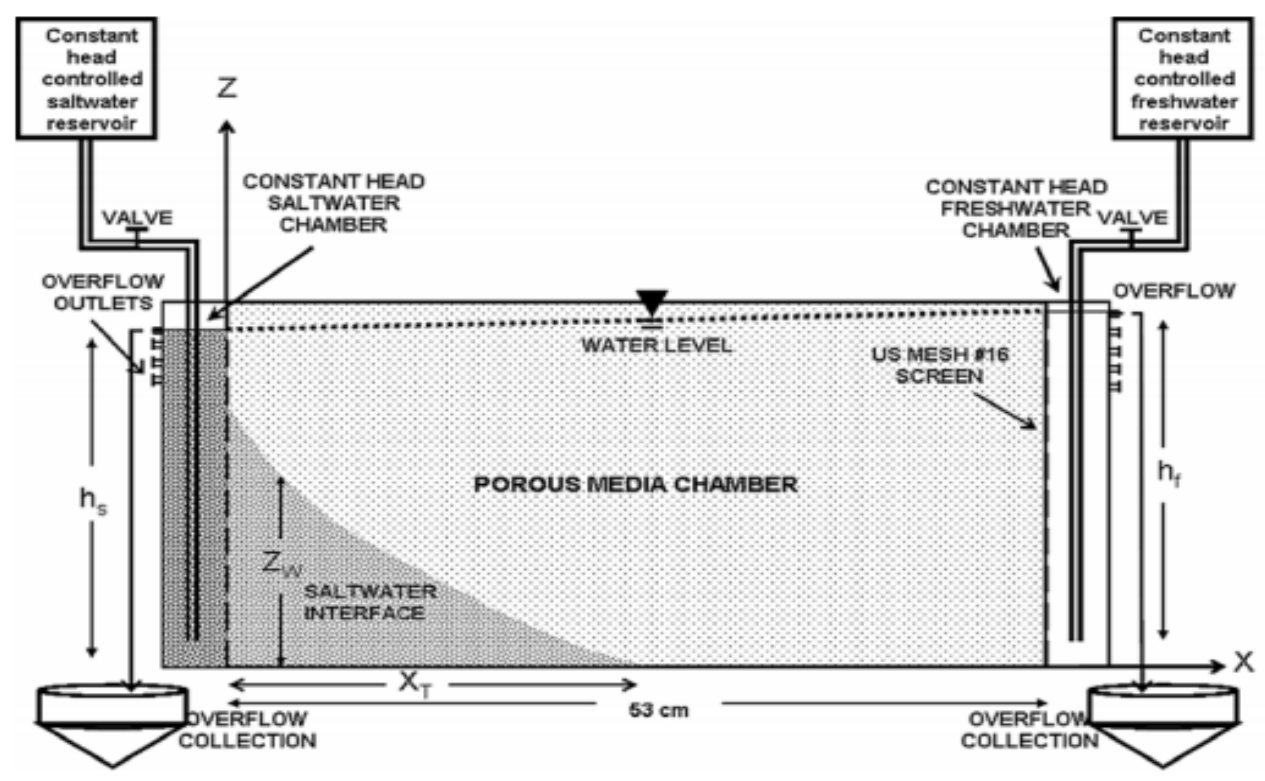

Şekil 4. Deney düzeneği şeması [24]

Çalışmada akiferde herhangi bir dış engel olmadan tuzlu suyun nasıl ilerlediğinin incelenmesi deneylerin ilk kısmını oluşturmuş, ardından tuzlu su girişimini engelleyici yapının olması durumunda tuzlu su gelişim kamasının durumunu gözlemişlerdir. Deneysel ortamda elde ettikleri sonuçları SEAWAT programı ile nümerik olarak da incelemişlerdir. Çalışmada kararlı bir akım durumu ve dış etkenler sonucunda hazırlanan modelin tuzlu su girişimi konusunda kullanılmasının uygun olduğu sonucuna varmışlardır. Luyun Jr. ve ark. [25] yaptıkları çalışmada yeraltındaki geçirimsiz bir perdenin tuzlu su girişimine olan etkisini incelemek için hem deneysel hem de nümerik yöntem kullanmışlardır (Şekil 5). 


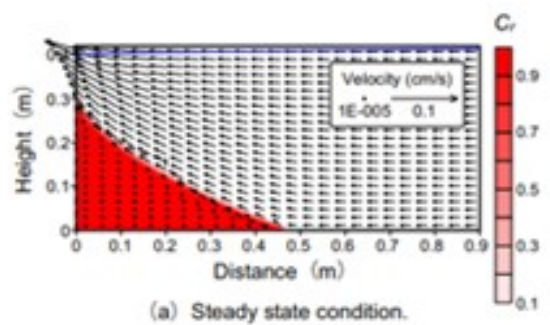

(a) Steady state condition.

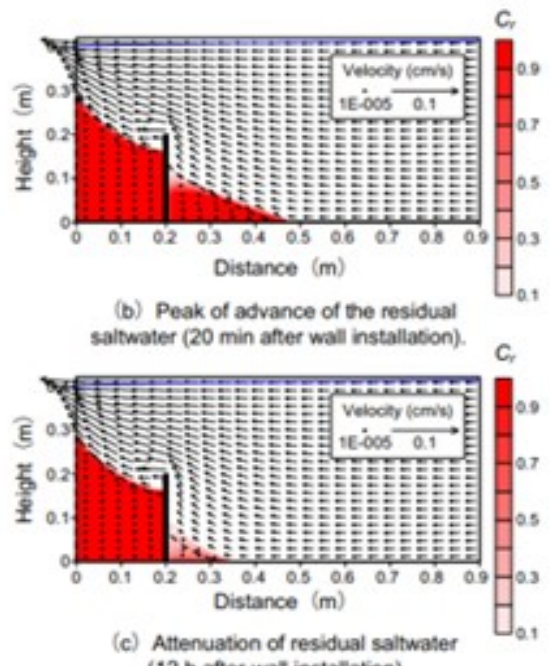

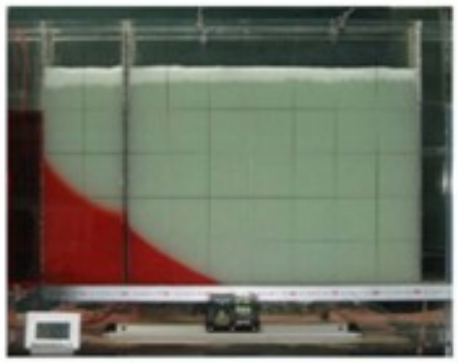

(a) Initial steady state condition

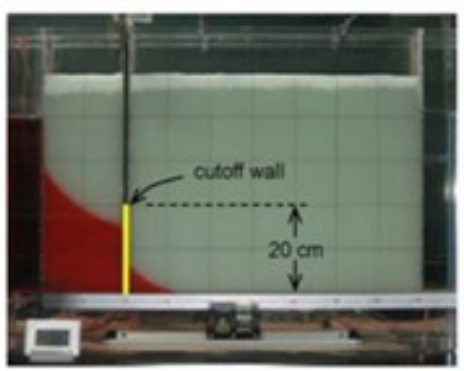

(c) Attenuation of residual saltwater ( $12 \mathrm{~h}$ after cutoff wall installation)

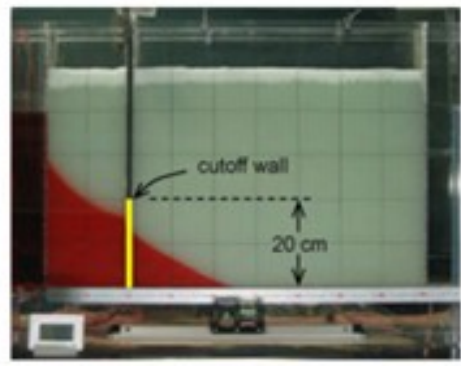

(b) Peak of advance of residual saltwater $(20 \mathrm{~min}$ after culoff wall installation)

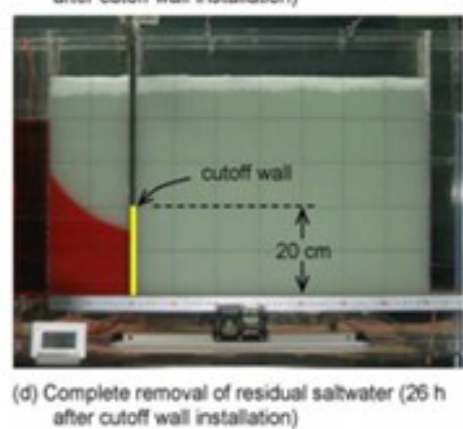

Şekil 5. SEAWAT kullanılarak modellenmiş bir deney örneği [25]

Başlangıç durumuna geçirimsiz perde eklendiğinde, ilerleme kaydeden tuzlu suyun zamanla geri çekilme davranışı gösterdiğini tespit etmişlerdir. Deney sonucunda tatlı suya yayılan tuzlu suyun tamamen geri çekildiğini gözlemlemişlerdir. Ancak bu geri çekilmenin sağlanabilmesi için minimum yüksekliğe sahip geçirimsiz bir perdenin kullanılması gerektiğini de belirtmişlerdir. İlaveten geçirimsiz perde yüksekliğinin tuzlu su çekilmesine olan etkisini de incelemişlerdir. SEAWAT yazılımı kullanılarak yapılan nümerik modelin, oluşan tuzlu su kamasını iyi temsil ettiğini vurgulamışlardır.

Bertorelle [26] tez çalışmasında homojen gözenekli yapı oluşturarak bir kıyı akiferinin deneysel ve nümerik olarak modellenmesi üzerine araştırmalarını gerçekleştirmiştir. Nümerik modelde tuzlu su kamasının topuk boyu ve karışım bölgesinin kalınlığının, kullanılan yeraltı barajının kıyıya olan mesafesine bağlı olarak değişimini simüle etmek için sonlu elemanlar yazılımı olan SUTRA programını kullanmıştır. Çalışma sonucunda tuzlu su girişimini engellemek amacıyla uygulanacak fiziksel bariyerin kıyıya olabilecek en yakın yerde konumlandırılmasının en etkili korumayı sağlayacağını belirlemiştir. Abdoulhalik ve Ahmed [27] çalışmalarında tabakalı homojen olmayan kıyı akiferlerinde geçirimsiz perdenin akım davranışı üzerindeki etkisini incelemişlerdir. Deney düzeneğini hazırlarken heterojen durumu temsil edebilmek için iki çeşit katmanlaştırma uygulamışlar, birinci durumda büyük taneli-ince taneli-büyük taneli (HLH) katmanlardan oluşan bir sistem kullanırken ikinci durumda ince taneli-büyük taneli-ince taneli (LHL) dizilim tasarlamışlardır. Homojen durum ile kıyaslandığında tabaka oluşumunun geçirimsiz perde performansını düşürdüğünü gözlemlemişlerdir. Aynı zamanda bu tabakaların tatlı su hızında değişimlere neden olduğunu tespit etmişlerdir. HLH durumunda ara yüzeyin 
konveks bir kama (wedge) şeklinde oluştuğunu ve LHL tabakalarında ortadaki düşük geçirgenliğe sahip tabakanın akımın hızını azalttığını belirtmişlerdir.

Abdoulhalik ve ark. [28] çalışmalarında geçirimsiz perde ve yarı geçirimli yeraltı barajlarını birlikte kullanarak yeni bir tuzlu su girişimini engelleme sistemi geliştirmişlerdir. Geleneksel olarak tek başına kullanılan fiziksel bariyer yöntemlerinin tuzlu su kamasına olan etkisini önerdikleri yeni bir bariyer ile karşıllaştırmışlardır. Laboratuvar deneylerinde kullandıkları tankı gözenekli bir yapıya uygun hale getirmek için belirli çaptaki cam boncuklardan (glass beads) faydalanmışlardır. Bu yeni yöntem ile tuzlu su kamasının ayak kısmında kaldırıcı etkiye sahip bir akım oluştuğunu gözlemişlerdir. Önerdikleri yeni fiziksel bariyer çeşidinin çok daha az maliyetli olduğunu ve pratikte kullanılmaya uygun olduğunu öne sürmüşlerdir. Chang ve ark. [7] çalışmalarında yeraltı barajlarının tuzlu su girişimine ve tatlı su akımına olan etkisini araştırmışlardır (Şekil 6).
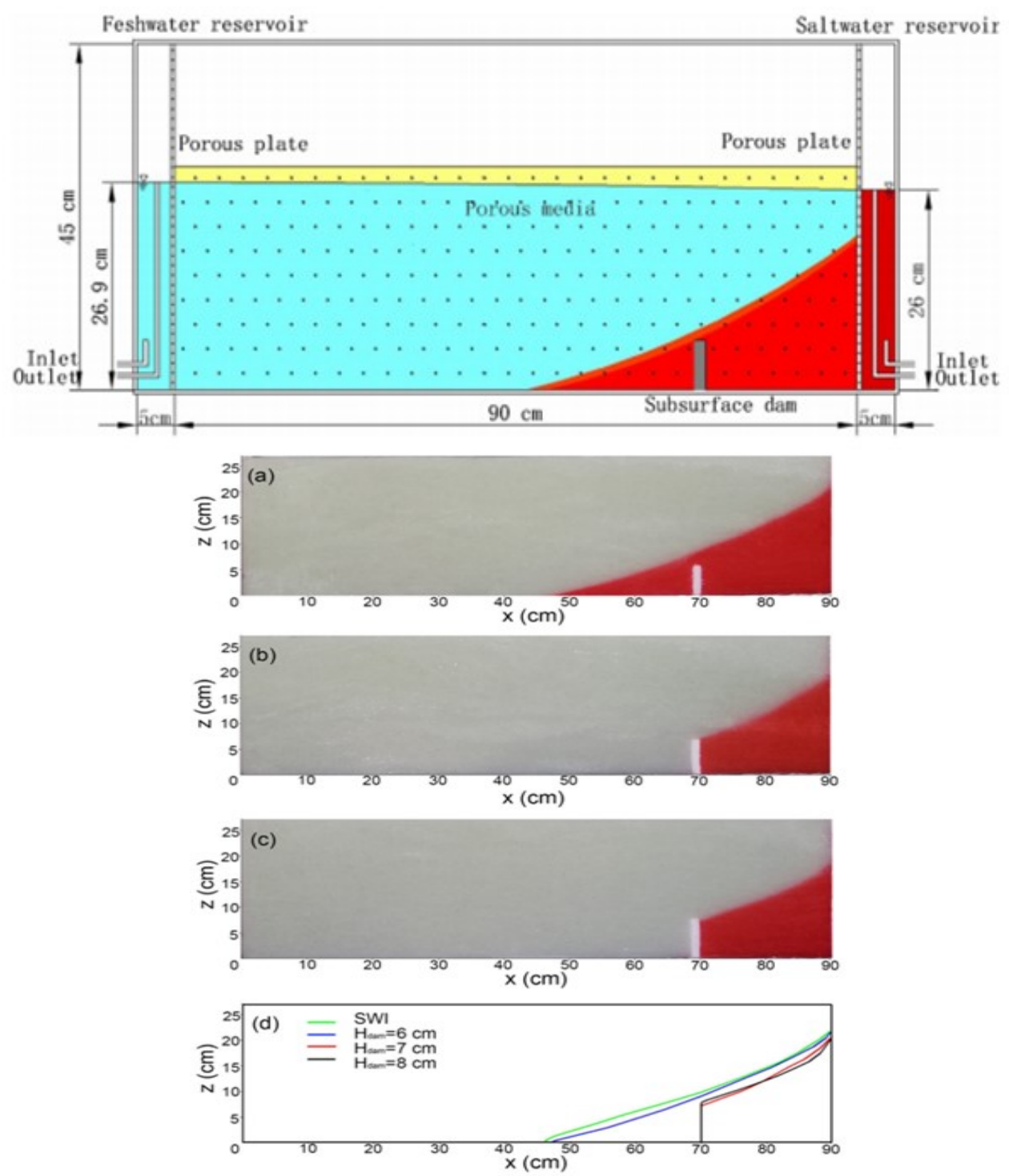

Şekil 6. Deney düzeneği şeması, anlık görüntüler ve seviye değiş̧imi grafiği [7] 
Barajın inşa edilmesi gereken minimum yüksekliğe ek olarak yeraltı suyu kullanımının çevresel etkileri üzerinde de durmuşlardır. Barajın yüksekliği, tuzlu su kaynağına olan mesafesinin değişmesi durumunda oluşacak senaryoları değerlendirmişlerdir. Baraj yüksekliği öngörülen değerin altında kalırsa tuzlu su geçişinin engellenemediğini ve buna bağlı olarak da tatlı su erişiminin sınırlandığını görmüşlerdir. Çalışmalarında hem nümerik hem de deneysel bir metot uygulamışlardır. Motevalli ve ark. [20] son zamanlarda insan faktörü etkisiyle artış gösteren akifer tuzluluğunu ele almışlardır. Ghaemshahr-juybar tuzlu girişimini engellemek için yeni bir çözüm önermişlerdir. Özellikle, GALDIT (Deniz suyu girişi) ve TAWLBIC (Tuzlu su yükselme) endekslerini, kıyıya komşu bölgelerde tuzlu su girişimine ve deniz suyunun kıyıda ne kadar ilerleyeceğini gösteren bir harita çıkarmak için kullanmışlardır. Hassas parametreleri belirlemek ve her üç yöntemde de katkıda bulunan faktörlerin optimum ağırlıklarını (tek parametreli yöntemle) elde etmek için tek parametre ve kaldırma katmanı duyarlılı̆̆ı analizi gerçekleştirmişlerdir. Üretilen üç optimize edilmiş yöntemi GALDIT-Opt, TAWLBIC-Opt ve CSI-Opt olarak ifade etmiş̧lerdir. Orijinal haritaların ve optimal olanların doğruluğunu değerlendirmek için Pearson korelasyonu kullanmışlardır. Sonuç olarak geliştirilen haritanın akiferlerde tuzlu suya hassas olan bölgeleri belirlemek için etkili bir araç olduğunu tespit etmişlerdir.

Abd-Elaty ve ark. [29] çalışmalarında ABD'nin Florida eyaletindeki Biscayne akiferinde tuzlu su girişiminin yeraltı bariyerleri ile engellenmesi üzerine nümerik bir inceleme yapmışlardır. Geçirimsiz perde ve yüzey altı barajı olarak iki çeşit bariyerin performansını incelemişlerdir. Tasarlanan sayısal modeller kıyaslama örneklerinin simülasyonu ile doğrulanmış ve Biscayne akiferinde ölçülen hidrolojik verilerden yola çıkarak varsayımsal verilerle bir vaka çalışması yapmışlardır. Uygulanan senaryolarda bariyerin derinliği, boyu ve permeabilitesini değiştirerek farklı denemeler gerçekleştirmişlerdir. Sonuçta fiziksel bariyerin çeşidi ne olursa olsun tatlı su akiferlerinde tuzlu su girişimini etkili bir şekilde engellediği görülmüş ve geçirimsiz perdelerin yeraltı barajlara göre tuzlu su girişiminde daha etkili olduğunu öne sürmüşlerdir. He ve ark. [30] çalışmalarında gel-git olaylarına sıkça maruz kalan nehir kanallarında tuzlu su girişiminin akım hızına ve akışkan yoğunluğunun dikey dağılımına olan etkisini incelemişlerdir. Deneysel olarak ve üç boyutlu bir model oluşturarak tuzlu su yayılımının kanal çeperlerindeki hidrostatik etkisini gözlemlemişlerdir. Ele alınan literatür örneklerinde kullanılan nümerik ve deneysel model çeşitleri ve bu modellerden elde edilen bulgular Tablo 1'de özetlenmiştir.

\section{Sonuçlar}

Küresel çapta yaşanan sıcaklık artışı, yerüstü kaynaklarında ortalamanın üzerinde su buharlaşmasına neden olmaktadır. Kıyı bölgelerinde yoğunlaşan nüfusun su ihtiyacının karşılanması için, dış etkenlere daha dayanıklı olan yeraltı barajları tercih edilmektedir. Ancak her doğal kaynakta olduğu gibi akiferlerin de sürdürülebilirliğini engelleyen diş etkenler bulunmaktadır, bu etkenler arasında en önemli olanlardan biri tuzlu su girişimidir. Tuzlu su girişimi sahil şeridinde yaşam kalitesini tehdit eden en önemli unsurlardan biridir ve gerekli önlemlerin alınabilmesi için tuzlu su girişimi sürecinin nasıl işlendiği detaylı olarak belirlenmelidir. Ayrıca tuzlu su girişimi önemli çevresel problemlere sebep olabileceğinden, olumsuz etkilerinin önlenebilmesi adına çözüm yöntemleri geliştirilmelidir. 
Tablo 1. Literatür özeti

\begin{tabular}{|c|c|c|c|}
\hline Yazarlar & Nümerik Model & Deneysel Düzenek & Bulgular \\
\hline Huyakorn ve ark. (1996) & $\begin{array}{l}\text { Matematiksel } \\
\text { Çözüm }\end{array}$ & - & $\begin{array}{l}\text { Galerkin sonlu elemanlar yöntemine } \\
\text { dayanan ynei bir metot önermişlerdir. }\end{array}$ \\
\hline $\begin{array}{l}\text { Goswami ve Clement } \\
\text { (2007) }\end{array}$ & SEAWAT & $\begin{array}{l}3 \text { Hazneli Dikdörtgen } \\
\text { Kesitli Deney Sistemi }\end{array}$ & $\begin{array}{l}\text { Kararlı ve kararsız durumlarda tuzlu } \\
\text { su girişimi modellemesi için Henry } \\
\text { probleminden daha Pratik bir yöntem } \\
\text { önermişlerdir. }\end{array}$ \\
\hline Luyun Jr.ve ark. (2009) & SEAWAT & $\begin{array}{l}3 \text { Hazneli Dikdörtgen } \\
\text { Kesitli Deney Sistemi }\end{array}$ & $\begin{array}{c}\text { Geçirimsiz duvar boyunun } \\
\text { azalmasının tuzlu su geri çekilme } \\
\text { sürecini hızlandırdığını tespit } \\
\text { etmişlerdir. }\end{array}$ \\
\hline Ishida ve ark. (2011) & - & - & $\begin{array}{l}\text { Yeraltı barajları ve uygulanma } \\
\text { yöntemleri hakkında bilgi verilmiştir. }\end{array}$ \\
\hline Bertorelle (2014) & SUTRA & $\begin{array}{l}3 \text { Hazneli Dikdörtgen } \\
\text { Kesitli Deney Sistemi }\end{array}$ & $\begin{array}{l}\text { Fiziksel bariyerin, kirletici tuzlu su } \\
\text { kaynağına olabilen en yakın mesafeye } \\
\text { konumlandırılması gerektiği } \\
\text { belirtilmiştir. }\end{array}$ \\
\hline $\begin{array}{l}\text { Abdoulhalik ve Ahmed } \\
\qquad(2017)\end{array}$ & SEAWAT & $\begin{array}{l}3 \text { Hazneli Dikdörtgen } \\
\text { Kesitli Deney Sistemi }\end{array}$ & $\begin{array}{l}\text { Önerilen yeni karma fiziksel bariyer } \\
\text { sisteminin mevcut yöntemlere kıyasla } \\
\text { daha etkili ve daha az maliyetle } \\
\text { uygulanabileceği vurgulanmıştır. }\end{array}$ \\
\hline Abdoulhalik ve ark. (2017) & SEAWAT & $\begin{array}{l}3 \text { Hazneli Dikdörtgen } \\
\text { Kesitli Deney Sistemi }\end{array}$ & $\begin{array}{c}\text { Gözenekli malzemeyi içeren } \\
\text { bölmeden uygulanan farklı poroziteli } \\
\text { katmanların tuzlu su girişimi } \\
\text { davranışını etkilediğini } \\
\text { belirtmişlerdir. }\end{array}$ \\
\hline Motevalli ve ark. (2018) & $\begin{array}{l}\text { TAWLBIC, } \\
\text { GALDIT ve CSI } \\
\text { modellerini } \\
\text { geliştirmişlerdir. }\end{array}$ & - & $\begin{array}{l}\text { Önerilen modeller kıyaslanarak, } \\
\text { akiferlerin tuzlu su girişimine olan } \\
\text { hassasiyetinin belirlenmesi için CSI } \\
\text { modelini uygun bulmuşlardır. }\end{array}$ \\
\hline Abd-Elaty ve ark. (2019) & SEAWAT & - & $\begin{array}{c}\text { Geçirimsiz duvarın yeraltı barajlarına } \\
\text { göre daha etkili bir tuzlu su girişimi } \\
\text { engelleme metodu olduğunu tespit } \\
\text { etmişlerdir. }\end{array}$ \\
\hline Chang ve ark. (2019) & SEAWAT & $\begin{array}{l}3 \text { Hazneli Dikdörtgen } \\
\text { Kesitli Deney Sistemi }\end{array}$ & $\begin{array}{l}\text { Efektif baraj yüksekliğinin en } \\
\text { optimum maliyet değerlerini elde } \\
\text { etmek tercih edilebileceğini } \\
\text { belirtmişlerdir. }\end{array}$ \\
\hline He ve ark. (2021) & $\begin{array}{l}\text { ANSYS } \\
\text { FLUENT }\end{array}$ & $\begin{array}{l}7 \text { m Uzunluğunda } \\
\text { Kanal Yapısı }\end{array}$ & $\begin{array}{c}\text { Kanallardaki su çekilme } \\
\text { davranışlarının tuzlu su girişimine } \\
\text { etkisini anlamak için önemli bir örnek } \\
\text { teşkil etmektedir. }\end{array}$ \\
\hline
\end{tabular}

Bu çalışmada, tuzlu su girişimi konusundaki güncel nümerik ve deneysel çalışmalar incelenerek konu hakkında bir literatür incelemesi sunulmuştur. Amaç ileride yapılabilecek araştırmalar için önemli katkılar sağlayabilmektir. Yapılan veya ele alınacak bu tür çalışmalar göstermektedir ki yeraltı akım dinamiğinin tuzlu su girişimi sonucunda nasıl değiştiğinin ortaya çıkarılmasında büyük rol oynamaktadır. Yeraltı akım davranışının etkin bir biçimde belirlenmesi düşük maliyetli ve efektif önlemlerin alınmasını da mümkün kılmaktadır. Türkiye'nin birçok yerinde yeraltı barajlarının yapımı su ihtiyacının karşılanması noktasında ve kuraklıkla mücadelede önemli çözümler olarak düşünülebilir. Sonuç olarak gelecekte su bütçesine yönelik hesaplamaların ve 
değerlendirmelerin yapılması, kıyı akiferlerinin efektif yönetim stratejilerinin geliştirilmesi, deneysel ve sayısal çözümler ile yeraltı suyu hareketi ve yayılımının ayrıntılı incelenmesi ve de uygun yer seçimleri ile yeraltı barajlarının daha çok sayıda uygulanabileceği imkanların hazırlanması çevre problemlerinin çözümü için önemli kazanımlar oluşturabilecektir.

\section{Kaynaklar}

[1]Karataş M, Çevik S. Stratejik doğal kaynak olarak su ve Türkiye'nin konumunun değerlendirilmesi. Akademik Araştırma Dergisi 2010; 45, 1-29.

[2]Sun Y, Xu SG, Kang PP, Fu YZ, Wang TX. Impacts of artificial underground reservoir on groundwater environment in the reservoir and downstream area. Int. J. Environ. Res. Public Health 2019, 16, 1921; doi:10.3390/ijerph16111921

[3]Freeze RA, Cherry JA. Yeraltı suyu. Ankara: Gazi Kitapevi 1979.

[4]Muluk Ç, Kurt B, Turak A, Türker A, Çalışkan M., Balkız Ö, Gümrükçü S, Sarıül G, Zeydanlı U. Türkiye'de suyun durumu ve su yönetiminde yeni yaklaşımlar: Çevresel perspektif, 2013. Erişim adresi: [www.tbcsd.org] [www.dkm.org.tr]104. Erișim tarihi: 24.05.2021

[5]Bear J, Cheng AHD. Theory and applications of transport in porous media. Modeling Groundwater Flow and Contaminant Transport 2010; 23. https://doi.org/10.1007/978-1-40206682-5 9

[6]Ishida S, Tsuchihara T, Yoshimoto S, Imaizumi M. Sustainable use of groundwater with underground dams. Japan Agricultural Research Quarterly 2011; 45(1), 51-61. https://doi.org/10.6090/jarq.45.51

[7]Chang Q, Zheng T, Zheng X, Zhang B, Sun Q, Walther M. Effect of subsurface dams on saltwater intrusion and fresh groundwater discharge. Journal of Hydrology 2019; 576, 508-519. https://doi.org/10.1016/j.jhydrol.2019.06.060

[8]T.C. Orman ve Su İşleri Bakanlığı, Devlet Su İşleri Genel Müdürlüğü. Erişim adresi: https://cdniys.tarimorman.gov.tr/api/File/GetFile/425/KonuIcerik/767/1115/DosyaGaleri/yerseciminden-isletmeye-yeralti-barajlari.pdf Erișim tarihi: 20.03.2021 [9]https://www.usgs.gov/mission-areas/water-resources/science/saltwater-intrusion?qtscience_center_objects=0\#qt-science_center_objects Erisim tarihi: 24.05.2021

[10]Richter BC, Kreitler CW. Geochemical techniques for identifying sources of ground water salinization 1993, CRC Press, Inc. Boca Raton, USA.

[11]Kilit M. Ada akiferinde tuzlu su girişiminin 3 boyutlu modellenmesi. 7. Kıyı Mühendisliği Sempozyumu 2011.

[12] Kavurmacı M, Elhatip H. Tuzlu göl sistemlerinde tuzlu Su-tatlı su arayüzey ilişkilerinin incelenmesi: Relations in salty lake systems: A case study. 68. Türkiye Jeoloji Kurultayı 2015; 190-191.

[13] Arslan H, Demir Y. Bafra ovasında deniz suyu girişiminin yeraltı suyu kalitesi üzerine etkisi. Anadolu Tarım Bilimleri Dergisi 2011; 26(2), 136-144.

[14] Oude Essink GHP. Improving fresh groundwater supply problems and solutions. Ocean Coastal Management 2001; 44, 429-449.

[15] İrtem E. Kıyı akiferlerinde tuzlanma ve kıyı akiferlerinin yönetimi. 6. Ulusal Kıy1 Mühendisliği Sempozyumu 2010; (312), 99-106. 
[16] Tully K, Gedan K, Epanchin-Niell R, Strong A, Bernhardt ES, Bendor T, Mitchell M, Kominoski J, Jordan TE, Neubauer SC, Weston NB. The invisible flood: The chemistry, ecology, and social implications of coastal saltwater intrusion. BioScience 2019; 69(5), 368-378. https://doi.org/10.1093/biosci/biz027

[17] Cooper HH Jr. A hypothesis concerning the dynamic balance of fresh water and salt water in a coastal aquifer. Journal of Geophysics Research 1959; 64 (4), 461-467.

[18] Bear J. Hydraulics of groundwater. New York, McGraw-Hill 1979; 569 p. USA.

[19] Giménez-Forcada E. Space/time development of seawater intrusion: A study case in Vinaroz coastal plain (Eastern Spain) using HFE-Diagram, and spatial distribution of hydrochemical facies. Journal of Hydrology 2014; 517, 617-627. https://doi.org/10.1016/j.jhydrol.2014.05.056

[20] Motevalli A, Moradi HR, Javadi S. A comprehensive evaluation of groundwater vulnerability to saltwater up-coning and sea water intrusion in a coastal aquifer (case study: Ghaemshahr-juybar aquifer). Journal of Hydrology 2018; 557, 753-773. https://doi.org/10.1016/j.jhydrol.2017.12.047

[21] Noorabadi S, Sadraddini AA, Nazemi AH, Delirhasannia R. Laboratory and numerical investigation of saltwater intrusion into aquifers. Journal of Materials and Environmental Science 2017; 8(12):4273-83. doi: 10.26872/jmes.2017.8.12.450

[22] Kumar CP. Management of groundwater in salt water ingress coastal aquifers. National Institute of Hydrology 2006; 540-560.

[23] Huyakorn PS, Wu YS, Park NS. Multiphase approach to the numerical solution of a sharp interface saltwater intrusion problem. Water Resources Research 1996; 32(1), 93-102

[24] Goswami RR, Clement TP. Laboratory-scale investigation of saltwater intrusion dynamics. Water Resources Research 2007; 43(4), 1-11. https://doi.org/10.1029/2006WR005151

[25] Luyun R, Momii K, Nakagawa K. Laboratory-scale saltwater behavior due to subsurface cutoff wall. Journal of Hydrology 2009; 377(3-4), 227-236. https://doi.org/10.1016/j.jhydrol.2009.08.019

[26] Bertorelle E. Laboratory experiments on the saltwater intrusion process. University of Padua 2014.

[27] Abdoulhalik A, Ahmed AA. The effectiveness of cutoff walls to control saltwater intrusion in multi-layered coastal aquifers: Experimental and numerical study. Journal of Environmental Management 2017; 199, 62-73. https://doi.org/10.1016/j.jenvman.2017.05.040

[28] Abdoulhalik A, Ahmed A, Hamill GA. A new physical barrier system for seawater intrusion control. Journal of Hydrology 2017; 549, 416-427. https://doi.org/10.1016/j.jhydrol.2017.04.005 [29] Abd-Elaty I, Abd-Elhamid HF, Nezhad MM. Numerical analysis of physical barriers systems efficiency in controlling saltwater intrusion in coastal aquifers. Environmental Science and Pollution Research 2019; 26(35), 35882-35899. https://doi.org/10.1007/s11356-019-06725-3

[30] He W, Jiang A, Zhang J, Xu H, Xiao Y, Chen S, Yu X. Hydrodynamic characteristics of lateral withdrawal in a tidal river channel with saltwater intrusion. Ocean Engineering $2021 ; 228$, 108905. https://doi.org/10.1016/J.OCEANENG.2021.108905 